\title{
Sociodemographic determinants of outcomes of children presenting to the Children's Emergency Room of a tertiary health institution in South Western Sahara
}

\author{
*Okoro Chidi Jude ${ }^{1}$, Emechebe George Ogonna ${ }^{1}$, Onyenwe Nathaniel Ejikeme ${ }^{2}$
}

Sri Lanka Journal of Child Health, 2019; 48(3): 233-239

\begin{abstract}
Introduction: In the past 4 decades, Under-5 mortality rates have remained high in south Western Sahara despite concerted efforts by healthcare providers. This is in contrast to significant gains made in other parts of the world.
\end{abstract}

Objectives: To review the sociodemographic characteristics of children presenting to the Children's Emergency Room (CHER) of Imo State University Teaching Hospital (IMSUTH), Nigeria with a view in identifying those characteristics that may affect their outcome.

Method: This is a prospective observational study of children presenting to the CHER of Imo State University Teaching Hospital located in Orlu, south west of the Sahara. Children were consecutively recruited over a period of 4 years into the study as they presented to the CHER. Pre-tested questionnaires were filled. Infants 2 months or less in age were excluded from the study. Data analysis was mainly descriptive using the statistical package for social sciences (SPSS) version for Windows. Both discrete and continuous variables were measured. Test for significance was done using Chi square test.

Results: Two thousand six hundred and forty nine children were recruited into the study of whom 234 $(8.8 \%)$ died, $49(1.9 \%)$ were discharged against medical advice, $47(1.8 \%)$ were referred out, 1265 $(47.8 \%)$ were transferred out and 1054 (39.8\%) were discharged home.

Conclusions: Majority of these children presented

${ }^{1}$ Imo State University Owerri, Nigeria, ${ }^{2}$ Igbinedion
University Okada, Nigeria
${ }^{*}$ Correspondence: jubhildr@yahoo.com
iD orcid.org/0000-0002-8246-5682
(Received on 13 October 2018; Accepted after revision on 16 November 2018)

The authors declare that there are no conflicts of interest

Personal funding was used for the project.

Open Access Article published under the Creative Commons Attribution CC-BY (CC) (i) late to the emergency paediatric unit, usually after 1 week of illness. Malnutrition, prior treatment at home before presentation by non-doctors, low socioeconomic status and presenting to emergency room at night were significantly associated with poor outcome.

DOI: http://dx.doi.org/10.4038/sljch.v48i3.8758

(Key words: Emergency, socioeconomic, outcomes, Sahara, under-5 mortality, paediatric)

\section{Introduction}

In the last 4 decades the under-five (U-5) mortality rates have remained high in South Western Sahara despite concerted efforts by health care providers ${ }^{1}$. The health related goals in the millennium developmental goals (MDGs) followed by the sustainable MDGs are the most recent attempts globally to reduce childhood mortality rates ${ }^{2}$. Significant gains were made in other parts of the world in contrast to the unremarkable reduction in childhood health indices in South West Sahara ${ }^{3}$. Infectious diseases like diarrhoea, malaria and lower respiratory tract infections were the most common causes of childhood morbidity and mortality in South West Sahara ${ }^{4}$

Studies in different diseases have shown that the duration of illness prior to presentation to hospital affects the outcome of the illness. Factors such as seeking after alternative care, fear of diagnosis and challenge of distance to available health facility have been adduced for the late presentation to hospital by different workers in this environment ${ }^{5,6}$. Low uptake of child survival strategies have been noted by various workers to occur in South Sahara ${ }^{7,8}$. Several studies have shown that the perception of the causes of disease of most people south of the Sahara, hinges on deep cultural beliefs which runs contrary to the biomedical concept of the causes of diseases $^{9,10,11}$. Witchcraft is at the centre of the causes of disease in these populations south of the Sahara; hence it is unlikely that these people will wholeheartedly accept healthcare interventions such as the childhood survival strategies conceived outside their beliefs as a solution to their health problems. These varied perceptions of the origin of diseases can be explained by the personality, the naturalistic and the biomedical theory ${ }^{12}$. In South West Sahara, the dominant theories on the 
perception of the causes of diseases are the personalistic and biomedical theories ${ }^{13}$. In the personality system of belief, illness is believed to be caused by the intervention of a supernatural being or a human being with special powers. In the naturalistic system of belief, a person's health is closely tied with the natural environment. Illnesses are due to imbalance between the environment and the human body. In biomedical theory, diseases are due to dysfunction of body systems and infection.

\section{Objectives}

This study attempts to review the sociodemographic characteristics of children presenting to the Children's Emergency Room (CHER) of Imo State University Teaching Hospital (IMSUTH), Nigeria with a view in identifying those characteristics that may affect their outcome.

\section{Method}

The study was carried out in the CHER of IMSUTH, Orlu. The hospital is located in the South eastern part of Nigeria south west of the Sahara. Geographically, Orlu is situated in the tropical rain forest. The CHER is open 24 hours of the day and every day of the week. Children admitted into CHER are stabilized usually within 48 to 72 hours, once out of danger they are transferred to appropriate children medical unit to complete their recovery or for those who have recovered, they are sent home from CHER. The cadre of doctors in the CHER ranges from consultants to house officers. Other members of staff included nurses and ward orderlies.

This is a prospective observational study of children presenting to the CHER of IMSUTH Orlu. Children were consecutively recruited into the study as they presented to CHER. This study was carried out over a period of 4 years (January 2014 to December 2017). Infants 2 months or less in age were excluded from this study. The only criterion for eligibility was being older than 2 months when presenting to the CHER. A pre-tested questionnaire was filled for each patient recruited into the study. Information requested in the questionnaire included age, gender, location (rural/urban), person who referred the patient, duration of illness before presentation, cadre of healthcare provider managing the patient before presentation, time at presentation, diagnosis, child's caregivers' belief about the origin of illness causation (the personality and the biomedicine theories) and outcomes (those who died, those who recovered fully and were discharged home, those who stabilized but were not fully recovered and were transferred to the ward after 72 hours and those who were discharged against medical advice). Social classes were assigned to each child based on the occupation and educational attainment of the parents or caregivers as described by Oyedeji and Ogunsaye $^{14,15}$. The outcomes of these children were divided into two main categories. Children with poor outcome included those who died, those who were discharged against medical advice or those who were referred out. Those with favourable outcome included those who were discharged and those who were stabilized and then transferred to the ward to complete their recovery.

Data analysis: Statistical analysis was mainly descriptive using the statistical package for social sciences SPSS version for Windows. Both discrete and continuous variable were measured and presented in frequency tables. Test for significance was done using Chi square test. A p-value of $<0.05$ was considered significant.

\section{Results}

Table 1 shows the relationship between the duration of illness in children prior to presentation and the various outcomes.

Table 1: Duration of illness prior to presentation to Children's Emergency Room

\begin{tabular}{|l|c|c|c|c|c|c|}
\hline \multicolumn{1}{|c|}{ Outcome } & 1week or $<$ & $>$ 1 week & Total & df & $\boldsymbol{\chi}^{\mathbf{2}}$ & p value \\
\hline Death n (\%) & $71(30.3)$ & $163(69.7)$ & $234(100)$ & 1.0 & 8.62 & $\mathbf{0 . 0 0 3 1}$ \\
\hline DAMA n (\%) & $19(38.8)$ & $30(61.2)$ & $49(100)$ & 1.0 & 0.22 & 0.6393 \\
\hline Referred out n (\%) & $21(44.7)$ & $26(55.3)$ & $47(100)$ & 1.0 & 0.14 & 0.712 \\
\hline Transferred out n (\%) & $530(41.9)$ & $735(58.1)$ & $1265(100)$ & 1.0 & 0.0243 & 0.8761 \\
\hline Discharge n (\%) & $448(42.5)$ & $606(57.5)$ & $1054(100)$ & 1.0 & 0.1462 & 0.7021 \\
\hline Total n (\%) & $1114(42.1)$ & $1535(57.9)$ & $2649(100)$ & - & - & - \\
\hline
\end{tabular}

DAMA: Discharged against medical advice

Of the 2,649 children who presented to the CHER, $57.9 \%$ children presented after 1 week of commencement of their illness as against $42.1 \%$ who presented within 1 week of their illness. Of the 234 children who died, $69.7 \%$ presented 1 week after commencement of their illness. This difference was statistically significant.

Table 2 shows the relationship between the weight of the child at the time of presentation and outcome of children presenting to CHER. 
Table 2: Weight per age at the time of presentation to Children's Emergency Room

\begin{tabular}{|l|c|c|c|c|c|c|c|}
\hline \multicolumn{1}{|c|}{ Outcome } & $\mathbf{8 0 \%}$ & $\mathbf{6 0 - 8 0 \%}$ & $<\mathbf{6 0 \%}$ & Total & df & $\boldsymbol{\chi}^{\mathbf{2}}$ & p value \\
\hline Death n (\%) & $73(31.2)$ & $58(24.8)$ & $103(44.0)$ & $234(100)$ & 2 & 25.712 & $\mathbf{0 . 0 0 0 0 1}$ \\
\hline DAMA n (\%) & $17(34.7)$ & $19(38.8)$ & $13(26.5)$ & $49(100)$ & 2 & 1.1017 & 0.1765 \\
\hline Referred out n (\%) & $18(38.8)$ & $13(27.7)$ & $16(34.0)$ & $47(100)$ & 2 & 1.144 & 0.5635 \\
\hline Transferred out n (\%) & $468(36.9)$ & $401(31.7)$ & $396(31.3)$ & $1265(100)$ & 2 & 11.537 & $\mathbf{0 . 0 0 3 1}$ \\
\hline Discharge n (\%) & $469(44.5)$ & $420(39.9)$ & $165(15.6)$ & $1054(100)$ & 2 & 175.4076 & $\mathbf{0 . 0 0 0 1}$ \\
\hline Total n (\%) & 1045 & 911 & 693 & 2649 & & & \\
\hline
\end{tabular}

DAMA: Discharged against medical advice

One thousand six hundred and four children presenting to CHER were malnourished, out of which 693 were severely malnourished. Out of 234 deaths recorded in CHER, $161(68.8 \%)$ were malnourished. These differences together with the outcomes for children who were transferred to the ward and those discharged were statistically significant.

Table 3 shows the relationship between time of the day at presentation and the outcome of children presenting to the CHER.

Table 3: Time of the day at presentation to Children's Emergency Room

\begin{tabular}{|l|c|c|c|c|c|c|c|c|}
\hline \multicolumn{1}{|c|}{ Outcome } & Morning & Afternoon & Evening & Night & Total & df & $\chi^{2}$ & \multicolumn{1}{c|}{ p value } \\
\hline Death n (\%) & $42(18.0)$ & $53(22.6)$ & $32(13.7)$ & $107(45.1)$ & $234(100)$ & 3 & 23.77 & $\mathbf{0 . 0 0 0 0 2}$ \\
\hline DAMA n (\%) & $10(20.4)$ & $10(20.4)$ & $13(26.5)$ & $16(32.7)$ & $49(100)$ & 3 & 2.009 & 0.57052 \\
\hline Referred out n (\%) & $08(17.0)$ & $11(23.4)$ & $13(27.7)$ & $15(31.9)$ & $47(100)$ & 3 & 3.546 & 0.3145 \\
\hline Transferred out n (\%) & $347(27.4)$ & $258(20.4)$ & $201(18.9)$ & $459(36.3$ & $1265(100)$ & 3 & 32.80 & $<\mathbf{0 . 0 0 0 0 1}$ \\
\hline Discharge n (\%) & $272(25.8)$ & $266(25.2)$ & $251(23.8)$ & $265(25.1)$ & $1054(100)$ & 3 & 54.65 & $<\mathbf{0 . 0 0 0 0 1}$ \\
\hline Total n (\%) & $679(25.6)$ & $598(22.5)$ & $510(19.3)$ & $862(32.5)$ & $2649(100)$ & - &. & - \\
\hline
\end{tabular}

DAMA: Discharged against medical advice

The highest number of children [862 (32.5\%)] presented to the emergency room at night while the lowest number of children [510 (19.3\%)] presented in the evening. Of the 234 children that died during the course of this study, $107(45.1 \%)$ deaths occurred at night while only $42(18 \%)$ deaths occurred in the morning. These differences were statistically significant.

Table 4 shows treatment supervision at home prior to presentation to the emergency room.

Table 4: Treatment supervision at home prior to presentation to Children's Emergency Room

\begin{tabular}{|l|c|c|c|c|c|c|c|c|c|}
\hline \multicolumn{1}{|c|}{ Outcome } & $\begin{array}{c}\text { Traditional } \\
\text { Medicine }\end{array}$ & $\begin{array}{c}\text { Medical } \\
\text { personnel } \\
\text { not doctors }\end{array}$ & $\begin{array}{c}\text { Medical } \\
\text { Doctors }\end{array}$ & $\begin{array}{c}\text { No } \\
\text { treatment }\end{array}$ & $\begin{array}{c}\text { Churches } \\
\text { Spiritual } \\
\text { healing }\end{array}$ & Total & df & $\chi^{2}$ & $\boldsymbol{p}$ value \\
\hline Death n (\%) & $67(28.6)$ & $55(23.5)$ & $48(20.5)$ & $45(19.2)$ & $19(8.0)$ & 234 & 4 & 17.92 & $\mathbf{0 . 0 0 1 3}$ \\
\hline DAMA n (\%) & $13(26.5)$ & $06(12.3)$ & $07(14.3)$ & $08(16.3)$ & $15(30.6)$ & 49 & 4 & 12.05 & $\mathbf{0 . 0 0 1 9}$ \\
\hline Referred out n (\%) & $15(31.9)$ & $07(14.9)$ & $06(12.8)$ & $09(19.2)$ & $10(21.3)$ & 47 & 4 & 8.850 & 0.0658 \\
\hline Transferred out n (\%) & $277(21.9)$ & $260(20.6)$ & $201(15.9)$ & $257(20.3)$ & $70(21.3)$ & 1265 & 4 & 161.76 & $\mathbf{0 . 0 0 0 1}$ \\
\hline Discharge n (\%) & $163(15.4)$ & $394(37.5)$ & $190(18.1)$ & $259(24.7)$ & $46(38.9)$ & 1049 & 4 & 212.3 & $\mathbf{0 . 0 0 0 1}$ \\
\hline Total n (\%) & 534 & 723 & 453 & 579 & 360 & 649 & - & - & - \\
\hline
\end{tabular}

DAMA: Discharged against medical advice

Of the 234 deaths that occurred in the emergency room during the period of study, $67(28.6 \%)$ had received unorthodox treatment supervised by the traditional medicine man. This was followed by 55 (23.5\%) deaths in children who received orthodox treatment supervised by medical personnel who were not doctors. Nineteen $(8.3 \%)$ deaths occurred in children who opted for spiritual healing in churches. The differences in the outcomes were statistically significant ( $p=0.0013)$. The differences in the various outcomes amongst the different groups of children who received treatment at home before presentation were statistically significant except for those children who were referred out.

Table 5 shows the relationship between caregivers' perception of the causes of diseases and outcome of children presenting to the children emergency room. 
Table 5: Caregivers' perception of causes of diseases of children presenting to Children's Emergency Room

\begin{tabular}{|l|c|c|c|c|c|c|}
\hline \multicolumn{1}{|c|}{ Outcome } & $\begin{array}{c}\text { Personality } \\
\text { theory }\end{array}$ & $\begin{array}{c}\text { Biomedicine } \\
\text { theory }\end{array}$ & Total & df & $\chi^{\mathbf{2}}$ & p value \\
\hline Death n (\%) & $205(87.6)$ & $29(12.4)$ & 234 & 1 & 82.438 & $<\mathbf{0 . 0 0 0 0 1}$ \\
\hline DAMA n (\%) & $44(89.8)$ & $05(10.2)$ & 49 & 1 & 10.2078 & $\mathbf{0 . 0 0 1 4}$ \\
\hline Referred out n (\%) & $39(83.0)$ & $08(17.0)$ & 47 & 1 & 4.450 & 0.380 \\
\hline Transferred out n (\%) & $864(68.3)$ & $401(31.7)$ & 1265 & 1 & 0.3488 & 0.5548 \\
\hline Discharge n (\%) & $738(70.0)$ & $316(30.0)$ & 1054 & 1 & 1.1037 & 0.2935 \\
\hline Total n (\%) & 1824 & 759 & 2649 & - & - & - \\
\hline
\end{tabular}

DAMA: Discharged against medical advice

The differences in the outcome of children between the 2 groups of perception of the causes of diseases were statistically significant for children who died in CHER and those discharged against medical advice.
Table 6 shows the relationship between socioeconomic status of the children presenting to CHER and outcome.

Table 6: Socioeconomic status of the children presenting to Children's Emergency Room

\begin{tabular}{|l|c|c|c|c|c|c|c|}
\hline \multicolumn{1}{|c|}{ Outcome } & Upper & Middle & Lower & Total & df & $\chi^{2}$ & p value \\
\hline Death n (\%) & $28(12.0)$ & $38(16.2)$ & $168(71.8)$ & 234 & 1 & 67.3842 & $<0.0001$ \\
\hline DAMA n (\%) & $08(16.3)$ & $11(22.5)$ & $30(61.2)$ & 49 & 1 & 131.1623 & $<0.0001$ \\
\hline Referred out n (\%) & $08(17.0)$ & $22(46.8)$ & $17(36.2)$ & 47 & 1 & 2.3265 & 0.3125 \\
\hline Transferred out n (\%) & $62(04.9)$ & $401(31.7)$ & $802(63.4)$ & 1265 & 1 & 344.465 & $<0.00001$ \\
\hline Discharge n (\%) & $311(29.5)$ & $520(49.3)$ & $223(21.2)$ & 1054 & 1 & 522.8876 & $<0.0001$ \\
\hline Total n (\%) & 417 & 992 & 1240 & 2649 & - & - & - \\
\hline
\end{tabular}

DAMA: Discharged against medical advice

One thousand two hundred and forty (46.8\%) children presenting to the emergency room during the study period had lower socioeconomic status. With regards to outcome in CHER, majority of the children with poor outcome had low socioeconomic status. Conversely those children presenting to CHER with good outcome, had upper and middle socioeconomic class. These differences were statistically significant.

\section{Discussion}

Of the 234 deaths which occurred during the study period, $70 \%$ occurred in children who presented to the CHER after one week of the onset of the illness $(p=0.0031)$. This is not surprising since infectious diseases such as diarrhoea, malaria and sepsis are the commonest reasons for admission into CHER in West Africa ${ }^{16}$. Delayed hospital presentation has been studied by many workers ${ }^{5,6,12,13}$. Reasons adduced for the delay in hospital presentation in most of the studies ${ }^{5,6,12,13,}$ include seeking alternative non-medical care, cultural influence on medical decision by extended family, fear of diagnosis, belief that diseases are caused by spirits, lack of funds and non-availability of appropriate medical care.

In this study, the nutritional status of the child seems to significantly affect the outcome of children admitted into CHER. Majority (44\%) of children who died were severely malnourished. Several studies have documented that severely malnourished children are at higher risk of dying than are healthy children and also these malnourished children have more severe disease episodes, associated with more complications, and also spend more time ill for each episode ${ }^{16,17,18}$.

The highest number of children $(32.5 \%)$ presented to the CHER at night and $45 \%$ of the total deaths occurred in children who presented at night. The majority of children who were discharged home with favourable outcome presented to the CHER during normal working hours. This is comparable to findings reported by Bhonagiri et $\mathrm{al}^{19}$ in their study in Australia, which showed increased mortality amongst patients admitted into ICU during off-hours (nights and weekend). However, this is in contrast to the findings obtained in a study by Morales et $\mathrm{al}^{20}$ where time of admission did not appear to correlate with patient outcome or mortality. The explanation for these significant differences in outcome noted in our study may be related to the fact that at night the hospital does not have the full complement of workers and support facilities for efficient health service delivery.

Majority (78\%) of children had received treatment at home prior to presentation at CHER and it is evident from this study that biomedical treatment (1176 children were treated at home with drugs) is the prevailing health seeking behaviour in this environment. However only $453(38.5 \%)$ of these children were supervised by qualified doctors. The rest were supervised by medical personnel such as nurses, medical laboratory technologists, patent 
medicine dealers and pharmacists. Similar observations were noted by Tinuade ${ }^{21}$ and his coworkers who reported that most mothers in their study used some form of home treatment with drugs bought over the counter in the first 24 hours of their children's illness prior to health facility presentation. In this study $20 \%$ children who presented to CHER had received medications supervised by traditional medical doctors. WHO in its $2002^{22}$ report revealed that $80 \%$ of people in Africa use traditional medicines at some point in their lives. Other workers in this part of the world have also noted that significant numbers of children are taken to the traditional doctors for medication. ${ }^{23,24,25}$ It is interesting to note from our studies that those children who received traditional medications at home prior to presentation in CHER had poorer outcome. Of the 234 children who died in CHER, 67 (28.6\%) were treated by traditional doctors at home, while $48(20.5 \%)$ were treated by qualified medical doctor $(\mathrm{p}=0.0013)$. This study also revealed that $30.6 \%$ of children whose caregivers signed against medical advice were receiving healing ministrations in churches for their illnesses.

Amongst the caregivers who presented to CHER in this study, the personality system of belief was dominant; in this system, illness is believed to be caused by the intervention of a supernatural being or a human being with special powers. Abubaka et $\mathrm{al}^{23}$ working in Kenya observed that when traditional healing system coexisted with biomedical system, traditional healing is preferred. In rural Tanzania. Dillip et $\mathrm{al}^{26}$ noted that the biochemical system was preferred to the traditional system. However he observed that in most cases they complement each other especially when the biochemical system has failed. Gunnama $\mathrm{L}^{24}$ in her work titled; A mother's choice: a qualitative study of mothers health seeking behavior for their children with acute diarrhea, reported that seeking health care from traditional practitioners is deeply ingrained in the culture of the society where diarrhoea is believed to be caused by supernatural causes. Mothers largely saw the two systems as complementary seamlessly switching between different healing options until remedy was found. This trend to a large extent explains the above findings and reflects their belief on the actual causes of diseases and illnesses were majority of children received treatment from non-medical personnel at home. This study further reveals that children whose caregivers had the personalistic view for the origin of diseases had significantly worse outcome such as those children who died in CHER and those who signed against medical advice when compared to those whose caregivers had the biomedical perspective for the origin of diseases. It is important to note that it is unlikely that these caregivers will wholeheartedly accept healthcare interventions such as the childhood survival strategies conceived outside their beliefs as a solution to their health problems.

Majority (46.8\%) of the children in this study were of the low socioeconomic class and a significant proportion of these children had poor outcome with $71.8 \%$ dying and $61.2 \%$ discharged against medical advice. Conversely, majority of children with better outcome belonged to the higher socioeconomic class. The socioeconomic indicators in this study were occupation, earning power of both parents and educational status of the caregivers, which determines the level of care for the child ${ }^{27}$. Increasing demand for healthcare facilities is a function of the level of education because they are more enlightened about orthodox medicine over traditional health care $^{28,29}$. The effect of parental income and intra family priorities on resource allocation on child health cannot be overemphasized. Inadequate income means the child is deprived of food for growth, living in overcrowded quarters, lack of preventive health care and poor educational attainment ${ }^{30,31}$. In general, women's access to and control over financial assess has strong correlations with improved nutritional outcomes and health preventive behaviors for their children $^{32}$.

In the four year period of study, 330 patients had poor outcome constituting $12.46 \%$ of the 2649 patients admitted into CHER. Two hundred thirty four patients died, 49 were discharged against medical advice and 47 were referred out.

\section{Conclusions}

- Majority of the children presenting to the CHER presented after one week of onset of illness or in the night when the hospital does not have the full complement of staff. Both factors were associated with a poor outcome in our study.

- Most patients presenting to CHER had received some form of treatment at home before presentation by medical personnel such as nurses, patent medicine dealers, laboratory technologists while some had their treatment at home supervised by traditional medical doctors and pastors who performed spiritual healing. Our study shows that this group of children was also associated with poor outcome.

- Low socio economic status was associated with poor outcome in this study.

\section{References}

1. World Bank mortality rates, Under 5 Data. Available from: https://data.worldbank.Org/indicator/SHDYN.MORT 
2. United Nations Millennium Development Goals. Available from:

www.un.org/millenniumgoals/

3. WHO| Children: reducing mortality. www.who.int/mediacentre/factsheet/fs178 /en/

4. Childhood diseases in Africa. WHO FACT Sheet N109 March 1969. Available from: www.who.int/mediacentre/factsheet/fs $109 /$

5. Adisa A.O, Aronolo OA, Akinkuohe et al. Metastatic breast cancer in a Nigerian Tertiary hospital. African Health Sciences 2011; 11(2):279-84.

PMid: 21857862 PMCid: PMC3158525

6. Oluseyi A, Adejumo O, Ayodeji A, Akinbodewa CO, Enajite I. Chronic liver disease in Nigeria: Late presentation is still the norm. Nigerian Medical Journal 2016; 57(3): 185-9.

https://doi.org/10.4103/0300-1652.184072

PMid: 27397961 PMCid: PMC4924403

7. Victoria CG, Hanson K, Bryce J, Vaughan JP. Achieving universal coverage with health interventions. Lancet 2004; 364 (9445): 1555-6.

https://doi.org/10.1016/S0140-

6736(04)17279-6

8. Schellenberg AJ, Abdulla S, Nathan R, Mukasa $\mathrm{O}$ et al. Effect of large scale social marketing of insecticide treated nets on child survival in rural Tanzania. Lancet 2001; 367(9264): 1241-7.

https://doi.org/10.1016/S01406736(04)172 79-6

9. Tinuade O, Iyabo RA, Durotoye O. Health care seeking behavior for childhood illnesses in a resource poor setting. Journal of Paediatrics and Child Health 2010; 46: 238-42.

https://doi.org/10.1111/j.14401754.2009.0

1677.x

PMid: 20337870

10. Cunnama L. Mothers' choice: a qualitative study of mothers' health seeking behavior for their children with acute diarrhoea. BMC Health Services Research 2016; 16: 669. https://doi.org/10.1186/s12913-016-19117

PMid: 27871282 PMCid: PMC5117598

11. Peltzer K. Utilization and practice of traditional complimentary/alternative medicine in South Africa. African Journal of Traditional, Complementary and Alternative Medicines 2009; 6(2):175-85.

12. Adesina OA, Olasoji AO, Ugboko VI. Reasons for late presentation of cleft deformity in north eastern Nigeria. Kanem Journal of Medical Sciences 2010; 4(1):257.

13. Adamu N, Usman A. Delayed presentation of patients with gynaecological malignancies in Kano, north western Nigeria. Open Journal of Obstetrics and Gynecology 2015; 5:333-48. https://doi.org/10.1186/s12913-016-19117

PMid: 27871282 PMCid: PMC5117598

14. Oyedeji GA. Socioeconomic and cultural background of hospitalized children in Ilesha. Nigerian Journal of Paediatrics 1985; 12(4): 111-7.

15. Olusanya O, Okpere E, Ezimokha M. The importance of social class in voluntary fertility control in a developing country. West African Journal of Medicine 1985; 4 : 205-12.

16. Man WDC, Weber M, Palmer A et al. Nutritional status of children admitted to hospital with different diseases and its relationship to outcome in the Gambia, West Africa. Tropical Medicine and International Health 1998; 3:678-86. https://doi.org/10.1046/j.13653156.1998.0 0329.x

PMid: 9735938

17. Yasmeen M, Ghaffar AS, Sayed S, ElKaraksy H. The effect of nutritional status on outcome of hospitalized in-paediatric liver disease patients. Journal of Clinical and Diagnostic Research 2016; 10(12):1-5.

18. Hgazi N, Zohreh M, Farid $Z$ et al. Nutritional assessment in critically ill patients. Iranian Journal of Medical Sciences 2016; 41(3): 171-9. 
19. Bhonagiri D, Pilcher DV, Bailey MJ. Increased mortality associated with afterhours and weekend admission to the intensive care unit: a retrospective analysis. Medical Journal of Australia 2011; 196:287-92.

20. Morales IJ, Peters SG, Afessa B. Hospital mortality rate and length of stay in patients admitted at night to the intensive care unit. Critical Care Medicine 2003; 31(3):85863.

https://doi.org/10.1097/01.CCM.00000553 78.31408 .26

PMid: 12626997

21. Tinuade O, Iyabo RA, Durotoye O. Health care seeking behavior for childhood illness in a resource poor setting. Journal of Paediatrics and Child Health 2010; 46:238-42.

https://doi.org/10.1111/j.14401754.2009.0

1677.x

PMid: 20337870

22. WHO 2002. WHO Traditional medicine strategy 2002-2005. Geneva.

23. Abubakar A, Van Baar A, Fischer R et al. Socio-Cultural determinants of health seeking behavior on the Kenyan coast: A qualitative study. PLoS ONE 2013; 8(11):e71998.

https://doi.org/10.1371/journal.pone.0071 998

PMid: 24260094 PMCid: PMC3832523

24. Cunnama L, Honda A. A mother's choice: a qualitative study of mother's health seeking behavior for their children with acute diarrhoea. BMC Health Services Research 2016; 16: 669.

https://doi.org/10.1186/s12913-016-19117

PMid: 27871282 PMCid: PMC5117598

25. Godfrey BS, Iyalomhe, Iyalomhe S. Health seeking baviour of rural dwellers in Sourthern Nigeria: Implications for health care professionals. International Journal of Tropical Disease and Health 2002; 2(2):62-71.
26. Dillip A, Alba S, Mshana $C$ et al. Acceptability- a neglected dimension of access to health care: findings from a study on childhood convulsion in rural Tanzania. BMC Health Services Research 2012; 12:112-3. https://doi.org/10.1186/1472-6963-12-113 PMid: 22571384 PMCid: PMC3405484

27. Adegboye AM. Socio-economic status category of rural dwellers in Northern Nigeria. Advances in Research 2016; 7(2):1-10. https://doi.org/10.1186/1472-6963-12-113 PMid: 22571384 PMCid: PMC3405484

28. Odubunmi AS, Omobitan O. Parental educational attainment and child health status in Nigeria. International Journal of Humanities and Social Sciences 2013; 3(16):152-61.

29. Omonijo DO, Anyaegbullam MC. A study of the socioeconomic status of work-study students of Convent University Ota. European Journal of Scientific Research 2015; 130(4):376-8.

30. Ahmed H. Effect of poverty on child health and pediatric practice in Nigeria: An overview. Annals of African Medicine 2007; 6(4):142-56.

https://doi.org/10.4103/1596-3519.55705

PMid: 18354938

31. Ismaila LS. Mothers income and child mortality in Southern Nigeria. Available from:

http://repository.upenn.edu/psc_african_de mography.

32. Schmidt EM. The effect of woman's intra household bargaining power on child health outcomes in Bangladesh. Undergraduate Economic Review 2012; 9 (1): art 4 